\title{
A EDUCAÇÃO DE EDMEA: CONCEPÇÕES EDUCATIVAS DE GRAMSCI NAS CARTAS DO CÁRCERE
}

\author{
Alessandro de Melo ${ }^{1}$ \\ Rosemary Dore Heijmans ${ }^{2}$
}

\section{RESUMO}

O objetivo deste texto é descrever e examinar a reflexão educacional de Gramsci nas Cartas do Cárcere, escritas durante o período de 1926 a 1937, especificamente sobre a educação dos filhos, Delio e Giuliano, e da sobrinha Edmea. Segundo se apreende das Cartas, Gramsci tinha como tema recorrente a luta contra o espontaneísmo, ou seja, apoiava a diretividade e a influência familiar e estatal na condução da educação das novas gerações. Outro tema bastante difundido no epistolário é a disciplina e o rigor nos estudos, bem como a crítica à especialização precoce.

Palavras-Chave: Gramsci; Cartas do Cárcere; Família e Educação.

\section{THE EDMEA EDUCATION: EDUCATIONAL CONCEPTS IN GRAMSCI'S LETTERS FROM PRISON}

\begin{abstract}
The purpose of this text is to describe and to examine the educational thought of Gramsci in letters from Prison, written during the period from 1926 to 1937, specifically on the education of children, Delio and Giuliano, and niece Edmea. According to the Letters, Gramsci had grasps as recurring theme to fight against the espontaneísmo, i.e., supported the family influence and directivity and the State in the conduct of the education of new generations. Another widespread theme in epistolary is the discipline and rigor in the studies, as well as the criticism of the early specialization.
\end{abstract}

Keywords: Gramsci; Letters from Prison; Family and Education.

\section{Introdução}

Este texto objetiva descrever e analisar as concepções educativas de Antonio Gramsci presentes nas Cartas do cárcere, correspondência que manteve com familiares entre os anos de 1926 e 1937. Optou-se por uma abordagem dos vários aspectos do projeto educativo encontrado, o que, evidentemente, não proporcionou um aprofundamento em cada um deles, dados os limites próprios do artigo.

Nas centenas de cartas publicadas postumamente, e que, somadas aos Cadernos do cárcere, são as principais obras de Gramsci, estão presentes preocupações de um homem apartado do convívio familiar de forma autoritária e violenta pelo regime fascista de Benito Mussolini. No cárcere, ele viveu atormentado pelas doenças, que fragilizou sobremaneira o seu espírito, e, ao mesmo tempo, pela distância dos entes queridos, em especial de seus filhos e da esposa, que nunca o pôde ver desde que foi preso.

A educação dos filhos e da sobrinha Edmea, que vivia na Sardenha, ocupa espaço não desprezível nas correspondências carcerárias de Gramsci e fornece um panorama bem definido do seu pensamento educacional, compondo uma unidade com seu pensamento sistematizado nos Cadernos, especialmente o Caderno 12. (GRAMSCI, 1986). 
O primeiro bloco de discussões é composto pela crítica ao espontaneísmo na educação dos filhos e as influências caóticas do ambiente, e em favor de uma intervenção dirigida pela família e pelo Estado na educação das novas gerações.

Outro bloco de discussão aqui apresentado refere-se às recomendações acerca da necessidade de que o desenvolvimento das crianças não fosse rifado pela precoce especialização, o que poderia conduzir ao aniquilamento das potencialidades presentes nas crianças e nos jovens.

Em Gramsci, enfim, a educação dos filhos não se relaciona ao desenvolvimento individualista, da eficiência individual para superar os outros e conquistar mesquinhamente um lugar ao sol. Sua proposta é a de formar um caráter revolucionário, forte o suficiente para não se dobrar frente às dificuldades. Dificuldades essas que ele havia conhecido quando esteve em Moscou, no início da revolução russa.

Vale ressaltar que Gramsci possuía uma resistência moral e física uma vez que enfrentou, no cárcere, uma batalha cotidiana contra as doenças que o afligiram, luta hercúlea como demonstram as cartas. Consideradas hoje como uma das maiores obras das ciências humanas do século XX.

\section{A luta contra o espontaneísmo: princípio educativo da presença familiar e do Estado na educação das novas gerações}

Dentre as várias dimensões da educação de seus filhos, assinaladas nas Cartas do Cárcere, encontra-se a necessária presença do adulto na condução da educação das crianças. Esse aspecto é percebido comumente nas "duas histórias pedagógicas paralelas" de Gramsci, como as definiu Manacorda (2008), referindo-se às histórias de Edmea ${ }^{3}$, filha de Gennaro, o irmão mais velho de Gramsci, e dos filhos Delio e Giuliano ${ }^{4}$, que viviam com a sua esposa, Giulia, que passou a viver na Rússia.

As cartas de Gramsci à Giulia expressam a angústia de um pai que não consegue mais acompanhar de perto o desenvolvimento e a vida cotidiana dos filhos. Este sentimento é ampliado pelo fato de a esposa não lhe escrever amiúde, relatando-lhe a vida dos meninos, o que terminou por gerar desgaste na relação de ambos.

A preocupação de Gramsci com os filhos é algo que se espera do pai distante, mas o grande número de cartas que ele dedica à formação da sobrinha é uma característica diferencial, devendo ser levada em conta. Ademais, morando na Sardenha, a sobrinha frequentava o sistema educativo italiano, sobre o qual Gramsci tinha mais conhecimento.

Gramsci tinha muita curiosidade a respeito das questões mais cotidianas, como as leituras feitas pelos filhos, os amigos da escola, as suas ocupações, quais eram suas aptidões, a relação com os animais, as conversas entre os meninos e Giulia etc. "O que me dói especialmente é a dificuldade ou a impossibilidade de saber com um certo grau de detalhe o desenvolvimento da vida dos meninos; e na vida dos meninos os detalhes é que importam". (Carta de 12 de março de 1927, GRAMSCI, 2005a, p. 125)

A própria relação entre os irmãos lhe inquietava: "Como Delio expressa sua função de irmão mais velho e experiente." (Carta de 8 de janeiro de 1927, GRAMSCI, 2005a, p.107). As fotografias, quando chegavam, eram oportunidades para Gramsci tentar mergulhar na vida dos filhos e, por isso, reclamava quando as fotografias não tinham boa qualidade. O prisioneiro sardo receava que Delio, com quem convivera um pouco, pudesse esquecer-se dele e, isso, aumentava a sua ansiedade.

Em geral, as cartas em que Gramsci dedicou atenção aos temas da educação dos filhos e da sobrinha possuem um caráter extremamente crítico, e uma crítica voltada para a atuação dos adultos, que ele considerava sempre insuficiente ou equivocada. Um exemplo 
disso refere-se à especial atenção que tinha no tocante ao desenvolvimento intelectual de Delio, considerado por Gramsci como atrasado para um menino de 5 anos de idade. Suas impressões, salvaguardado o fato de que apenas podia opinar a partir do que lhe escreviam sobre as crianças, eram as de que faltava um direcionamento mais efetivo da família de Giulia no encaminhamento da sua educação. Havia muito mais "espontaneísmo" do que "coerção". Esta, no entanto, é necessária à formação histórica do homem, como escreve:

\begin{abstract}
Mas, do conjunto geral destes dados, tive a impressão de que a concepção sua e do resto de sua família seja excessivamente metafísica, isto é, pressuponha que na criança está em potência todo o homem e é necessário ajudá-la a desenvolver o que já contém em estado latente, sem coerções, deixando agir as forças espontâneas da natureza ou seja lá o que for. Ao contrário, eu penso que o homem é toda uma formação histórica obtida com a coerção (entendida não só no sentido brutal e de violência externa), e é só o que penso: de outra forma se cairia numa forma de transcendência ou imanência. (Carta de 30 de dezembro de 1929, GRAMSCI, 2005a, p.385-386).
\end{abstract}

Nessa carta, Gramsci expressa não apenas a preocupação de um pai, mas de um intelectual para o qual o desenvolvimento humano não é função de um estado a priori, de algo já preexistente, independente das ações externas, históricas e sociais. Tal era a orientação de alguns métodos da escola ativa, de acordo com os quais a criança era pensada como um "novelo", que já continha em si todo o conhecimento e o papel do professor consistia apenas em puxar o fio do rolo, vindo à tona o conteúdo já existente no interior do "rolo".

Este modo de conceber a educação como o desenrolamento de um fio preexistente teve sua importância quando se contrapunha à escola jesuítica, isto é, quando negava uma filosofia ainda pior, mas hoje está igualmente superado. Renunciar a formar a criança significa só permitir que sua personalidade se desenvolva acolhendo caoticamente, do ambiente geral, todos os motivos de vida. ${ }^{5}$ (Carta de 30 de dezembro de 1929, GRAMSCI, 2005a, p. 386). ${ }^{6}$

Aquela orientação não diretiva, como observa Gramsci, se justificava na crítica ao modelo jesuíta, tal como fizera Rousseau. Mas, aquele momento fora superado e se tornava necessário assumir conscientemente a direção do processo educativo. Por isso, Gramsci atribui grande importância ao papel do professor e à presença da família na educação da nova geração. Para Gramsci, agiam, portanto, não somente o pai, mas o intelectual consciente de que as crianças não poderiam ser deixadas à criação pelos elementos ambientais, que caoticamente atuavam sobre elas ${ }^{7}$.

Outro aspecto que gerou divergências na relação de Gramsci com sua esposa Giulia foi o fato de esconderem de Delio a sua condição de prisioneiro na Itália, situação esta com a qual Gramsci não concordava, pois acreditava ser necessário contar ao filho a verdade. Na discussão desse problema, ele apresenta sua concepção de infância.

Eu penso que é conveniente tratar as crianças como seres já razoáveis e com as quais se fala seriamente até das coisas mais sérias; isto lhes causa uma impressão muito profunda, reforça o caráter, mas especialmente evita que a formação da criança seja deixada ao acaso das impressões do 
ambiente e à mecanicidade dos encontros fortuitos. (Carta de 15 de dezembro de 1930, GRAMSCI, 2005a, p. 463).

A insistência de Gramsci em manter forte o caráter da criança é uma das heranças trazidas de sua própria vida, pela superação das dificuldades pelas quais passou desde que saiu de casa e pela doença que o assolou desde criança. A trajetória de luta pela vida de um menino da Sardenha, cujo destino foi extremamente modificado e prejudicado com a prisão do pai, Gramsci a levou consigo para o resto da vida, servindo-lhe como parâmetro de avaliação do caráter das pessoas com as quais convivia ${ }^{8}$. É famosa a carta dirigida a Carlo, seu irmão mais jovem, na qual critica duramente a fraqueza do irmão frente à vida, relembrando episódios de sua própria vida desde a saída de casa para estudar. Conclui a carta afirmando ter sido justamente a sua difícil trajetória que moldou o seu caráter. (Carta de 12 de setembro de 1927, GRAMSCI, 2005a, p. 188-191) ${ }^{9}$.

A primeira referência sistemática à educação da sobrinha Edmea aparece em carta endereçada à sua mãe Peppina (Giuseppina Marcias Gramsci, 1861-1932). Nessa carta, repleta de lembranças da infância, Gramsci tenta encorajar a sua mãe a superar o trauma de ter o filho encarcerado. Além disso, reforça o cuidado especial que a família deve dedicar a Mea, pois, não tendo os pais presentes, ela não teria lembranças como as que pôde ter da mãe, que com "[...] suas mãos sempre ocupadas em nosso benefício, para nos aliviar os sofrimentos e buscar alguma utilidade em todas as coisas." (Carta de 26 de fevereiro de 1927, GRAMSCI, 2005a, p.121). Sua mãe sempre foi um alicerce moral para o sardo.

A questão levantada por Gramsci em suas lembranças da mãe, cujas atitudes reforçaram o seu caráter por toda a vida, não poderiam acontecer com Mea, devido à ausência de seus pais. A falta de lembranças, de exemplos como os que Peppina lhe havia dado, influiria sobre o desenvolvimento do caráter de Mea. A ausência de referência dos pais na vida de Mea deveria ser preenchida com os cuidados de sua avó Peppina e de sua tia Grazietta.

O fortalecimento moral de Edmea, na concepção de Gramsci, deveria ser feito, em primeiro lugar, no tato e na objetividade de não lhe esconder a verdade sobre o seu pai, exilado na França naquele momento e sem possibilidade de retornar ao país ${ }^{10}$.

Outro princípio educativo presente nas cartas sobre Mea é o da elevação do particular ao universal, ou seja, a superação da "vida fossilizada do vilarejo". Ampliar a visão de mundo, não só geograficamente, mas também do ponto de vista da criatividade, é de extrema importância para a educação das crianças, como aparece, por exemplo, na relevância dada por Gramsci à literatura.

Quando o sardo aconselha sua mãe sobre como deveria ser contada para Mea a verdade a respeito da ausência do pai, aparece o caráter universalizante do pensamento de Gramsci:

Devem lhe explicar que seu pai hoje não pode voltar do exterior e isto se deve ao fato de que Nannaro [apelido de Gennaro Gramsci], tal como eu e muitos outros, pensamos que as muitas Edmeas que vivem neste mundo deveriam ter uma infância melhor do que a que tivemos e ela mesma tem. (Carta de 26 de fevereiro de 1927, GRAMSCI, 2005a, p.121).

Ainda em relação aos sobrinhos Gramsci aconselha que seus parentes deixem que Edmea se envolva com o ambiente do vilarejo sardo em que vivia. Essa orientação se deve ao fato de sua família não ter permitido a Edmea desenvolver a língua sarda, o que "[...] prejudicou sua formação intelectual e colocou uma camisa-de-força em sua fantasia." (Carta de 26 de março de 1927, GRAMSCI, 2005a, p. 133). Conhecendo de perto a 
limitação dos dialetos para a aquisição de uma cultura universal, como era o caso do dialeto falado por sua família, mesmo assim Gramsci considerava fundamental o seu domínio, para a maior integração de Mea ao seu ambiente e para soltar suas fantasias. A retirada desse elemento fundamental da "natureza" sarda, a língua, deixava as crianças duplamente prejudicadas: não aprendem um bom italiano e nem um bom sardo. É nesse sentido que Gramsci escreve à sua irmã Teresina, pedindo-lhe para não cometer o mesmo "erro" na educação de Franco.

Aconselho você, de coração, a não cometer este erro e a deixar que suas crianças absorvam todo o sardismo que quiserem e se desenvolvam espontaneamente no ambiente natural em que nasceram: isto não será um obstáculo para o futuro delas, longe disso. (Carta de 26 de março de 1927, GRAMSCI, 2005a, p.134).

A inserção no ambiente cultural de origem não significa, do ponto de vista gramsciano, desenvolver uma relação passiva e exterior com o ambiente, abandonando os princípios universalistas da educação. Ao contrário, conviver no ambiente cultural originário é, também, tornar-se apto a superá-lo, a ir além dele, a não se deixar esmagar pela mediocridade dos que não possuem horizontes mais elevados do que a vida cotidiana do lugar. Tal confronto propiciaria um verdadeiro movimento contraditório de adaptação e superação.

A concepção de Gramsci sobre o "ambiente" também aparece em uma carta a seu irmão Carlo, datada de 25 de agosto de 1930, na qual volta a avaliar o ambiente em que Mea é criada, definindo-o de forma mais minuciosa do que fizera três anos antes. Agora, Gramsci denomina "ambiente" as próprias pessoas que estão lidando com Edmea, portanto, o próprio irmão Carlo, as irmãs, a mãe, os amigos, a escola, enfim, todo o vilarejo no qual ela vive.

Além da família, diretamente interessada na educação de Mea, vários outros fatores estão em competição na influência direta ou indireta do desenvolvimento da menina. Gramsci pergunta: "De quais partes deste ambiente Mea vai receber os estímulos para formar seus hábitos, seus modos de pensar, seus juízos morais?". (Carta de 15 de agosto de 1930, GRAMSCI, 2005a, p. 439). Partindo desse questionamento, insere a importância fundamental da família na definição dos rumos a serem percorridos por Mea, conferindolhes uma base moral, intelectual e psíquica saudável, de modo a proporcionar-lhe um caráter forte e inteligência para superar as dificuldades da vida.

Se vocês renunciarem a intervir e a guiá-la, usando a autoridade que vem do afeto e da convivência familiar, fazendo pressão sobre ela de modo afetuoso e amoroso, mas inflexivelmente rígido e firme, acontecerá, sem dúvida nenhuma, que a formação espiritual de Mea vai ser o resultado mecânico da influência casual de todos os estímulos deste ambiente [...]. (Carta de 15 de agosto de 1930, GRAMSCI, 2005a, p. 439).

A avaliação, portanto, da família na condução da educação das crianças é um fato inquestionável em Gramsci, como se pode apreender nesta citação da carta de agosto de 1930. A seguir será tratado o tema da crítica gramsciana à especialização precoce.

\section{Especialização precoce e disciplina na educação}


Em várias cartas de Gramsci aparece a sua preocupação com a especialização precoce de seus filhos, em meio ao debate sobre a educação na Rússia, a qual, apesar de não possuir muitas informações, apresenta um posicionamento questionador das reformas encaminhadas naquele país, já sob o governo de Stálin. Gramsci trata, por exemplo, das "brigadas de assalto" ou "método de laboratório por pelotões, a variante soviética do Plano Dalton". (MANACORDA, 2008, p. 107), bem como os "nichos especializados", também conhecidos como "cantinhos vivos", por meio dos quais as crianças poderiam ter contato com animais vivos, plantas e outros objetos ${ }^{11}$. Gramsci compartilha com sua esposa o receio sobre aqueles métodos e o seu interesse em conhecê-los melhor quando lhe solicita mais detalhes sobre a vida escolar dos filhos.

tenho muito interesse em saber como foi inserido na escola primária o princípio das brigadas de assalto ${ }^{12}$ e os nichos especializados e qual o objetivo pedagógico se propõem alcançar. Pode nascer a dúvida de que isto acelere artificialmente a orientação profissional e distorça as inclinações das crianças, fazendo perder de vista o objetivo da escola única de conduzir as crianças a um desenvolvimento harmonioso de todas as atividades, até que a personalidade formada acentue as inclinações mais profundas e permanentes, porque nascidas num nível mais alto de desenvolvimento de todas as forças vitais, etc., etc. (Carta de 14 de dezembro de 1931, GRAMSCI, 2005b, p.134)

Gramsci expressa nesta carta sua crítica a qualquer metodologia que leve a uma especialização precoce e artificial da criança, estimulando experiências parciais sem lhe oferecer oportunidades para desenvolver outras perspectivas no sentido de criar condições para o amadurecimento de suas inclinações.

Outra observação de Gramsci sobre a especialização diz respeito à sua discordância quanto ao caráter naturalizador da concepção de "inclinação" das crianças, quando lhes é imposta, desde a mais tenra idade, a formação profissional. São imposições que as crianças ainda não podem se resguardar de seus efeitos. Dessa forma, e se contrapondo à alusão de Giulia em relação às "inclinações" de Delio e Giuliano, Gramsci esclarece como entende as inclinações das crianças $^{13}$ :

Acredito que, em cada um deles, coexistam todas as tendências, tal como em todas as crianças, tanto para a prática quanto para a teoria ou a fantasia, e que, de fato, seria correto guiá-los neste sentido, para um ajuste harmonioso de todas as faculdades intelectuais e práticas, que podem se especializar no tempo apropriado, com base numa personalidade vigorosamente formada em sentido total e integral. (Carta de 1 de agosto de 1932, GRAMSCI, 2005b, p. 224-225)

Trata-se de generalizar o modelo de "Leonardo Da Vinci":

O homem moderno deveria ser uma síntese daquelas características que são [...] hipostasiadas como características nacionais: o engenheiro americano, o filósofo alemão, o político francês, recriando, por assim dizer, o homem italiano do Renascimento, o tipo moderno de Leonardo da Vinci transformando-o em homem-massa ou homem coletivo, ainda que mantendo sua forte personalidade e originalidade individual. (Carta de 1 de agosto de 1932, GRAMSCI, 2005b, p.225). 
Em seguida Gramsci expõe seu questionamento a respeito do Método Dalton e se tal método, aplicado na Rússia, levava à criação de "Leonardos". O Método Dalton criado por Helen Parkhurst (1887-1973) é pouco citado nos Cadernos do Cárcere, mas a sua característica predominante, segundo Gramsci, é a liberdade proporcionada aos estudantes para o estudo. Não eram, de acordo com ele, senão a extensão para a escola média da forma como se desenvolviam os estudos na universidade italiana ${ }^{14}$.

Outro elemento relacionado ao método pedagógico, presente nas Cartas do Cárcere, refere-se ao kit meccano ${ }^{15}$. Gramsci presenteou Delio com este kit no seu aniversário de 04 anos, com o objetivo de lhe propiciar condições para o desenvolvimento de atividades práticas que exigiam ação corporal, força e coordenação motora, adequadas aos "meninos modernos". A escolha do meccano, no entanto, não foi feita sem certa insegurança quanto à sua eficácia como brinquedo, pois poderia privar "[...] a criança de seu próprio espírito inventivo." (Carta a Giulia de 14 de janeiro de 1929, GRAMSCI, 2005a, p. 312).

Ao refletir sobre o meccano e sobre as possíveis aptidões demonstradas por Delio em utilizá-lo, Gramsci relembra um momento de sua formação escolar, quando os professores se dedicavam ao desenvolvimento das aptidões dos estudantes. "Eu, quando menino, tinha inclinação muito acentuada para as ciências exatas e a matemática. Perdi-a durante os estudos ginasiais, porque não tive professores que valiam mais que zero à esquerda." (Carta de 9 de abril de 1928, GRAMSCI, 2005a, p. 258).

A importância que o revolucionário italiano dava à fantasia aparece em diversos momentos de uma carta a Giulia "Portanto, fico contente com o fato de que Delio ame as obras de fantasia e ele próprio faça fantasias; não acredito que, por isso, não possa se transformar em um grande "engenheiro" construtor de arranha-céus ou de centrais elétricas, pelo contrário." (Carta de 1 de junho de 1931, GRAMSCI, 2005b, p. 51). Mas, esta carta também evidencia que a educação deveria estar voltada para o equilíbrio das aptidões. Assim, gostar de arte não significaria deixar de lado o gosto pelas ciências exatas. Ao contrário, o gosto pela fantasia também poderia ser um indício das inclinações de Delio para ser um engenheiro mais completo ou um homem mais humanizado pelo equilíbrio das aptidões e conhecimentos estéticos, artísticos e científicos.

A tendência de Gramsci a apoiar as disposições mais distintas nas atividades dos filhos é evidenciada em outra carta enviada a Giulia, declarando seu contentamento pelo fato dos filhos Giuliano e Delio caçarem rãs. O ato de caçar, e se sujar para isso, é compreendido como ação positiva para o desenvolvimento das crianças. Sobre isso solicita de Giulia uma informação: "Gostaria de saber se se trata ou não de rãs comestíveis, o que daria à atividade de caçador um caráter prático e utilitário que não deve ser desprezado." (Carta de 31 de agosto de 1931, GRAMSCI, 2005b, p. 80). O caráter "não desprezível” da utilidade da ação de caçar rãs, sublinhado por Gramsci, é mais um elemento no rol de críticas à escola ativa. Esta, apesar de ter seu fundamento na ação dos estudantes, não concebia a ação como necessariamente portadora de sentido.

A formação da força física e moral é também um importante princípio educativo para Gramsci, que soma-se à questão do equilíbrio entre as aptidões naturais, ou seja, aquelas que são de herança dos pais para os seus filhos, com àquelas que são construídas ao longo da vida objetiva. Sobre essa questão Gramsci expressa as suas dúvidas, de forma poética, no trecho de uma carta a Delio, sem data determinada.

\section{Querido Delio}

Sinto-me um pouco cansado e não posso escrever muito. Mas me escreva sempre e de tudo que lhe interessa na escola. Penso que você gosta de história, tal como eu gostava quando tinha sua idade, porque se refere aos homens vivos, e tudo o que se refere aos homens, ao maior número 
possível de homens, a todos os homens do mundo enquanto se unem entre si em sociedade, trabalham, lutam e melhoram a si mesmos - tudo isto só pode lhe dar prazer, mais do que qualquer outra coisa. Mas será que é assim mesmo?

Abraços Antonio.

(Carta de 31 de agosto de 1931, GRAMSCI, 2005b, p. 80).

Nessa carta, também, sobressai como princípio educativo a universalidade, o horizonte dos interesses propostos por Gramsci ao seu filho, como trilha de desenvolvimento pessoal, intelectual e moral. Interessar-se pela história dos homens que não significa apenas conhecimento, mas, sobretudo se aliar a um objetivo comum, ao bem comum, que é o ethos revolucionário por excelência. Se, por um lado, a prisão de Gramsci o afastou fisicamente da maior parte de seus entes queridos e companheiros de luta, por outro não o desumanizou, algo contra o qual sempre lutou na prisão, que é um locus por excelência da fragmentação humana.

Outro aspecto da crítica de Gramsci à educação dada à sobrinha Edmea, especificamente ao desenvolvimento de suas potencialidades, refere-se à falta de outras ambições da menina, "[...] a não ser cuidar de aparências [...]" (Carta de 28 de julho de 1930, GRAMSCI, 2005b, p. 435). Gramsci imputa a responsabilidade dessa situação ao excesso de "mimo" que a família supostamente dedicava à sobrinha. Por isso, recomenda: "Em suma, tentem acostumá-la a trabalhar com disciplina e restringir um pouco sua vida 'mundana': menos sucessos na vaidade e mais seriedade em termos de substância." (Carta de 28 de julho de 1930, GRAMSCI, 2005b, p. 435).

Outra característica forte nas cartas sobre a educação de Edmea é a insistência da disciplina nos estudos realizados pela sobrinha. Dirigindo-se ao seu irmão Carlo, Gramsci comenta uma carta que recebera de Edmea, cujo conteúdo e a qualidade e espontaneidade das frases, bem como o modo pelo qual a sobrinha conseguira expressar seus sentimentos muito lhe emocionaram (Carta de 31 de dezembro de 1928). Esses aspectos também são valorizados por Gramsci em muitas cartas relativas aos filhos. No entanto, ele destaca a quantidade de erros da menina, mesmo considerando que estava então na terceira série. Para Gramsci, os erros se devem à pressa com que ela "deve" escrever e até mesmo falar "comendo" as palavras, "engolindo" os erres etc.

Ainda sobre a produção escrita da menina, Gramsci observa a necessidade de os familiares acompanhar os deveres de casa: "Deve-se ter o cuidado de mandá-la fazer os deveres com aplicação e muita disciplina". (Carta de 31 de dezembro de 1928, GRAMSCI, 2005a, p. 308).

A disciplina é, portanto, um aspecto fundamental da concepção pedagógica de Gramsci. Como menciona em outras cartas, a disciplina deve ser obtida segundo as possibilidades da idade da sobrinha, pois não é possível aplicar às crianças o mesmo ritmo e a mesma intensidade dos estudos aplicados aos adultos. De qualquer forma, as crianças devem ser habituadas a uma disciplina tal que, desde a infância, seja possível desenvolver um caráter e uma disciplina para os estudos.

$\mathrm{Na}$ concepção gramsciana de educação, encontra-se também uma divisão concernente à puberdade ${ }^{16}$. Escrevendo a Carlo sobre a puberdade, Gramsci afirma que esta divide a personalidade e o psiquismo em dois períodos, nos quais a educação deve agir de modo diferenciado. Antes da puberdade, há maior possibilidade de atuação dos adultos sobre as crianças. Depois disso, a relação se torna mais problemática. 
$\mathrm{Na}$ verdade, o que acontece é que os pais sentem a responsabilidade em relação aos filhos exatamente neste segundo período, quando é tarde: então, naturalmente, entra em cena o porrete e a violência, que, no fim das contas, dão bem poucos frutos. Em vez disso, por que não se ocupar da criança no primeiro período? Parece pouco, mas o hábito de ficar sentado de cinco a oito horas por dia é uma coisa importante, que pode ser inculcado até os quatorze anos sem sofrimento, mas em seguida não se pode mais. (Carta de 25 de agosto de 1930, GRAMSCI, 2005a, p. 441).

Nesta carta Gramsci evidencia que a "coerção" não significa autoritarismo. Para ele, ao contrário, deve prevalecer o princípio antiautoritário dos adultos, especialmente sobre os adolescentes. Ao mesmo tempo, porém, mostra que o papel interventor dos pais na condução da educação dos filhos, desde a mais tenra idade, possibilita-lhes uma relação mais harmoniosa, principalmente quando os filhos chegam à adolescência, relação mediada por sentimentos não baseados na violência.

Em sua última carta dirigida à formação de Edmea, Gramsci apresenta uma verdadeira lição de vida de um revolucionário que, mesmo enfrentando um estado de saúde gravíssimo, abatendo-o de forma inexorável já em 1933, não deixa de lado a necessidade de dedicar à sobrinha um apoio moral para o seu futuro, centrando o foco, como sempre, nos estudos e na atitude frente à vida. Dirigindo-se à sua irmã Teresina, Gramsci chama a atenção para a sua própria serenidade, mesmo diante das situações mais adversas da prisão, para ressaltar o valor do esforço de concentração, conceito a ser repassado para Edmea:

Não pense que eu tenha perdido, sequer por um momento, nenhuma pontinha de minha serenidade, como você diz. No máximo, quando me sinto fisicamente fraco, perco a vontade de me ocupar com qualquer coisa que seja alheia a minha preciosa pessoa física; acontece como quando se deve fazer um grande esforço para levantar determinado peso, trincam-se os dentes e não se fala nada, para que se possa concentrar inteiramente no esforço imediato [...] Parece-me que deve explicar este conceito a Mea, para que não perca a coragem e continue a estudar de todos os modos; numa hipótese infeliz, ela pode perder alguns anos como tempo material numa determinada sequência escolar, mas não os perderá inteiramente se melhorar a cada dia sua cultura, seu preparo geral, se ampliar o horizonte de seus conhecimentos e de seus interesses intelectuais. (Carta de 3 de abril de 1933. GRAMSCI, 2005b, p. 323-324).

Estas palavras de um tio preocupado com o futuro da sobrinha demonstram a concepção de Gramsci sobre a educação e a relevância do papel da cultura geral na formação humana. Em resumo, disciplina, força de vontade, objetivo a ser alcançado, conhecimento e cultura geral perfazem os princípios mais importantes da concepção gramsciana de educação nas Cartas do Cárcere. Tais princípios estão presentes em suas críticas, ou desconfianças, sobre a reforma educativa na Rússia, que levava, ou poderia levar, a uma profissionalização precoce por meio de uma educação unidirecional.

\section{Considerações Finais}

A leitura das Cartas do Cárcere, de Antonio Gramsci, é uma experiência que transcende a mera interpretação objetiva de seu conteúdo, algo importante mas que deve ser somado ao que as Cartas têm de realmente únicas. Elas mostram a vida cotidiana, os 
anseios, as angústias, os sofrimentos e os sonhos de um revolucionário cuja vida foi interrompida violentamente por um regime autoritário. Consequentemente, também foi interrompido um enorme potencial intelectual, já revelado por Gramsci no texto sobre a questão meridional, escrito pouco antes de sua prisão, em 1926.

As Cartas revelam também que o rompimento da vida de Gramsci se configurou em um drama familiar: separou-o da mãe, dos irmãos, dos sobrinhos na Sardenha; e, também, tão doloroso quanto isso, separou um pai de seus dois filhos e de sua esposa.

A prisão, no entanto, fez construir uma amizade, eternizada pela edição das Cartas, com a sua cunhada Tânia, relação esta permeada por carinho, companheirismo e, também, muita tensão, pois Gramsci nunca foi famoso por ser uma personalidade fácil, e isso ele mesmo testemunha em inúmeras cartas.

As milhares de linhas escritas sob a pressão da censura, e muitas vezes escritas obrigatoriamente em dias e horários não determinados por ele, retratam um Gramsci educador. É um pai e um tio que, ao se preocupar com o destino de seus filhos Delio e Giuliano, e de sua sobrinha Edmea, traça um conjunto de reflexões que conseguem ser vivas até hoje, fazendo-nos refletir sobre educação de uma forma ampla e densa, o que torna as Cartas do Cárcere também um clássico educacional pouco explorado.

A centralidade da concepção educativa nas Cartas se dá pela luta contra o espontaneísmo e da especialização precoce e a disciplina. Subjacente a estes temas, percorrendo todo o epistolário dedicado à educação dos filhos e da sobrinha, está o posicionamento de Gramsci a respeito da educação moral e do caráter, aspectos fundamentais para tornar seus pequenos entes queridos adultos fortes e realizados. Falar em "realização" num mundo dividido entre governantes e governados poderia parecer inconcebível. Contudo, para Gramsci, realização significa o desenvolvimento máximo das potencialidades humanas, intelectuais e morais.

Para sintetizar o que aqui foi tratado, destaca-se em primeiro lugar o papel da família na condução do desenvolvimento intelectual e do caráter dos fillhos. Os valores mais importantes do desenvolvimento intelectual e moral, a disciplina em relação à vida e aos estudos para possibilitar às crianças, quando adultas, enfrentar corajosamente as dificuldades desse mundo "grande e terrível", são tarefas a serem assumidas pelos entes que educam as crianças.

Vivendo em um meio áspero desde a infância, a concepção educativa de Gramsci não poderia ser outra senão a de uma educação rigorosa, voltada a disciplinar as novas gerações para o estudo e, portanto, recusando toda e qualquer espontaneidade sem direção ou responsabilidade. Não é casual sua insistência, em muitas cartas, na direção rigorosa dos adultos sobre a formação das crianças, mas, também, o valor atribuído à criação autônoma dos filhos e da sobrinha, no que respeita à criação estética, à relação com atividades práticas ou à expressão escrita.

Finalmente, uma temática bastante pertinente nas discussões das Cartas é a crítica radical de Gramsci à especialização precoce das crianças. Gramsci defende a oferta de oportunidades às crianças para o desenvolvimento de suas mais variadas aptidões, permitindo-lhes o contato com as artes, as atividades práticas, literárias, esportivas, construtivas etc. Seu horizonte é a formação do "Leonardo" como "homem-massa" moderno. Deriva desta concepção sua crítica aos métodos da escola soviética, que levavam à redução da concepção do trabalho ao exercício de atividades práticas, principalmente na fábrica, enfim, limitando-a apenas a atividades industriais e levando à precocidade das especializações.

A leitura das Cartas de Gramsci contribui tanto para conhecer as relações familiares e as concepções de educação para os filhos e a sobrinha, quanto para compreender a 
continuidade do seu projeto für ewig (que dure para sempre), apresentado nos Cadernos do cárcere. Desta forma, a análise da escola unitária ${ }^{17}$ e de todos os conceitos dela derivados podem ser enriquecidos com as Cartas, algo também secundarizado na literatura educacional brasileira de base gramsciana.

\section{Referências}

FIORI, Giussepe. Vida de Antonio Gramsci. Buenos Aires: Peón Negro, 2009.

GRAMSCI, Antonio. Cuadernos de la cárcel. 5 Tomos. Edición crítica del Instituto Gramsci a cargo de Valentino Gerratana. Ciudad del Mexico: Ediciones Era, 1981.

Letttere dal cárcere 1926-1937. Edizione elettronica a cura dell'International Gramsci Society. 1986.

Cartas do cárcere. v.1. 4.ed. Tradução de Luiz Sérgio Henriques. Carlos Nelson Coutinho (Org.). Rio de Janeiro, RJ: Civilização Brasileira, 2005a.

Cartas do cárcere. v.2. 4.ed. Tradução de Luiz Sérgio Henriques. Carlos Nelson Coutinho (Org.). Rio de Janeiro, RJ: Civilização Brasileira, 2005b.

DORE, Rosemary. Educação e escola nos cadernos do cárcere. Anais...25 Reunião Anual da Anped, Caxambu, 2002, paginação irregular. Disponível em:

http://webcache.googleusercontent.com/search?q=cache:7iIq3QaBcpAJ:www.anped.org.br /reunioes/25/rosemarydoresoarest17.rtf+\&cd=1\&hl=pt\&ct=clnk\&gl=br. Vários acessos.

. Gramsci, o estado e a escola. Ijuí, RS: Unijuí, 2001.

MANACORDA, Mario Aliguiero. O princípio educativo em Gramsci: americanismo e conformismo. Campinas, SP: Alínea, 2008.

\section{Notas}

\footnotetext{
${ }^{1}$ Universidade Estadual do Centro-Oeste.

${ }^{2}$ Universidade Federal de Minas Gerais.

${ }^{3}$ Edmea, ou simplesmente Mea, como carinhosamente lhe chama Gramsci, é sua sobrinha, filha de seu irmão mais velho, Gennaro Gramsci (1884-1965). Quando seu irmão foi lutar na Espanha Mea foi deixada aos cuidados de Grazietta Gramsci (1887-1962), irmã de Gramsci. Ao longo do epistolário do cárcere, Gramsci se mostra claramente preocupado com a educação de Mea.
}

${ }^{4}$ Delio Gramsci (1924- 1981); Giuliano Gramsci (1926 - 2007).

${ }^{5}$ Em uma carta dirigida a Teresina, sua irmã, datada de 17 de novembro de 1930, Gramsci lhe conclama que, mesmo em meio às dificuldades, deveria se manter forte justamente "[...] para poder orientar bem as crianças fora da escola e não deixa-las abandonadas a si mesmas, como muitas vezes ocorre especialmente nas famílias ditas 'respeitáveis"”. (GRAMSCI, 2005a, p. 455)

${ }^{6}$ Sobre a escola ativa, Dore (2002) afirma que ela constitui, no pensamento de Gramsci nos Cadernos uma espécie de "involução" em relação ao modelo jesuíta de educação. Classifica-o também de "transformismo" presente na Reforma Gentile, ou seja, sob o arcabouço de novidade, na verdade a ênfase ao "espontaneísmo" acaba por reforçar o status quo ante. É na reforma educacional de Gentile que se adota a concepção inatista de que "[...] o cérebro da criança seja como um novelo que o mestre ajuda a desenrolar." (C. 1, p. 114, versão eletrônica italiana de Valentino Gerratana). Os valores da criatividade e da atividade presentes na concepção de escola ativa deveriam, para Gramsci, serem cotejados com os princípios de formação humanista e 
científica. A escola unitária é escola ativa em sua fase clássica, ou seja, despojada dos princípios espontaneístas e impondo como central o papel dos adultos na condução da educação das novas gerações.

${ }^{7}$ Neste trecho encontra-se o fundamento da concepção de espontaneísmo nas Cartas, ou seja, que as crianças, sem terem o amparo e a presença sistemática da família, fossem educadas conforme as caóticas influências externas, do ambiente, sobre as quais não é possível ter controle e cujos resultados são impossíveis de antecipar.

${ }^{8}$ Refere-se aqui à prisão de Francesco Gramsci, pai de Gramsci. Ele foi preso em 9 de agosto 1898 e, segundo Fiori (2009, p. 22-24), as razões foram políticas, dado o fato de que Ciccilo apoiou um candidato que acabou derrotado nas eleições locais de 1897. Por uma artimanha política, acusaram o pai de Gramsci, que era o responsável pelo Cartório de Registro, de “[...] desfalque, concussão e de falsidade em documentos públicos.” (FIORI, 2009, p. 23). A condenação foi de cinco anos, oito meses e vinte e dois dias, justamente quando Antonio Gramsci tinha apenas 7 anos e começava a mostrar os sinais de sua deformidade física.

${ }^{9}$ Sobre tal tema não é possível esquecermos uma linda passagem de uma carta em que Gramsci relembra o papel de sua mãe na educação dos filhos, ressaltando a sua coragem e determinação, mesmo tendo que criar sozinha os filhos, após a prisão do marido. "De resto, você nem pode imaginar quantas coisas eu lembro em que aparece sempre como uma força benéfica e cheia de ternura por nós. [...] Como todas as recordações que temos de você são de bondade e de força e você deu suas próprias forças para nos criar, isto significa que já está no único paraíso real que existe, o qual, para uma mãe, acho que é o coração dos próprios filhos". (Carta de 15 de junho de 1931, GRAMSCI, 2005b, p.53).

${ }^{10}$ Gennaro Gramsci (1884-1965), teve uma longa vida dedicada ao socialismo, chegando a influenciar Gramsci. Foi Tesoureiro da Câmara do Trabalho em Cagliari, quando abrigou seu irmão, então estudante do curso colegial. Foi, posteriormente, Secretário da seção local do Partido Socialista Italiano. Foi administrador do jornal L'Ordine Nuovo, entre 1921 e 1922. Foi exilado na Espanha, mas chegou a visitar por duas vezes o irmão encarcerado, em nome dos comunistas italianos no exílio. Gennaro ainda lutou na Guerra Civil Espanhola (1936-1939) contra o fascismo de Franco, numa unidade anarquista.

${ }^{11}$ Em uma carta datada de 7 de dezembro de 1931, escreve Gramsci para a cunhada Tânia sobre os "cantinhos vivos": "Vou ficar contente se me escrever sobre os novos métodos de educação que mencionou no cartão, porque, acredito, sempre houve crianças que brincam com passarinhos vivos, com bolas de gude, ou levam seus objetos prediletos para a cama. O que se deve ver é se mudou a relação entre as crianças e as coisas, isto é, se se consegue despertar nas crianças um novo modo de conceber a natureza e a vida." (Carta de 7 de dezembro de 1931, GRAMSCI, 2005b, p. 127-128).

12 Segundo Manacorda (2008, p.107) 'Parece-me que, por 'brigadas de assalto', se deva entender o 'método de laboratório por pelotões', variante soviética ('a tradução em russo', tem-se vontade de dizer) do Plano Dalton concebido por Helen Parkhurst; uma variante que consistia em aceitar o princípio do planejamento do trabalho autônomo dos alunos, afastando-se porém os riscos do individualismo pela acentuação do trabalho em grupo."

${ }^{13}$ Gramsci assim se refere à concepção da esposa, na mesma carta de 01 de agosto de 1932: "Também aquilo que escreve sobre Delio e Giuliano e suas inclinações me fez recordar que, há alguns anos, você acreditava que Delio tivesse muita inclinação para a engenharia de construção, enquanto parece que hoje esta é a inclinação de Giuliano e, ao contrário, Delio se volta mais para a literatura e a construção...poética. Na verdade, devo dizer que não acredito nestas inclinações genéricas tão precoces e confio pouco em sua capacidade de observar as tendências de ambos para uma orientação profissional." (Carta de 1 de agosto de 1932, GRAMSCI, 2005b, p.224).

${ }^{14}$ Estas anotações sobre o Método Dalton aparecem nos Cadernos 9, parágrafo 119 (Questões Escolásticas) e no famoso parágrafo 1 do Caderno 12. Nas Cartas o Método Dalton é citado apenas na Carta do dia 01 de agosto de 1932. De fato, a relação entre o Método Dalton e a especialização precoce continua um campo aberto a discussões e pesquisas, o que não é o objetivo deste artigo. Uma interpretação, desenvolvida brevemente por Manacorda (2008), relaciona este método ao projeto de industrialização soviética dos anos 30. Dore (2001), no capítulo de seu livro dedicado à "Escola única do trabalho" desenvolve de forma mais densa esta discussão. O percurso da autora retoma os apontamentos de Marx e Engels sobre educação, assim como o processo histórico da relação entre trabalho e educação nos períodos da manufatura à grande indústria, pontuando a participação estatal neste processo, por meio das Leis dos Pobres, as Leis Fabris e o Estatudo dos Artesãos. A mesma autora afirma que a concepção educativa de Marx deve ser lida no contexto de desenvolvimento da maquinaria na indústria, e as mudanças daí advindas para a formação dos trabalhadores, que com isso supera a fragmentação do trabalho típico do período artesanal e manufatureiro, 
direcionando a formação para a "desespecialização" ou "politecnia". (DORE, 2001, p.337). Na União Soviética a concepção adotada por Lênin e Krupskaya também era inspirada nos princípios expostos pelos formuladores da filosofia da práxis. Foi a esposa de Lênin, inclusive, que propôs a alteração para "ensino geral e politécnico" no programa do Partido Comunista, reformulado em 1917, visando justamente superar a limitação da especialização inerente ao termo "formação profissional", presente no programa do partido anteriormente. A politecnia, no sentido proposto por Krupskaya, pretendia formar "capacidades de trabalho universais", sujeitos "capazes de qualquer trabalho", vinculando ensino e trabalho produtivo. (DORE, 2001, p. 364). Em síntese, o que ocorreu, segundo a autora, e comprovado pelo testemunho escrito de Krupskaya, é que houve uma prática reducionista da relação entre trabalho e educação, secundarizando o papel da escola em detrimento da fábrica, algo que se chocava com a concepção de Lênin, a qual ligava "[...] os fundamentos teóricos da tecnologia científica e sua relação com a sociedade". (DORE, 2001, p. 365), que, portanto, não defendia uma formação reduzida à atividade produtiva industrial ou técnica, mas social e política.

${ }^{15}$ Segundo os organizadores das Cartas do Cárcere, o kit meccano foi inventado no início do século XX e fez sucesso na década de trinta. O kit continha "[...] peças metálicas, parafusos e porcas para montar diferentes objetos [...]". (GRAMSCI, 2005a, p. 260).

${ }^{16} \mathrm{Na}$ carta de 25 de agosto de 1930, citada neste parágrafo, Gramsci não apresenta outro parâmetro para a análise da puberdade que não seja a sua própria experiência e dos seus irmãos, em especial Carlo, a quem se dirige. Portanto, parece que as questões levantadas por ele não devem ser lidas como "ciência", assim como ele mesmo a distingue do senso comum. No entanto, tem valor para o registro de seu projeto educativo tal como ele vem sendo abordado neste texto.

${ }^{17}$ Embora não seja o objetivo deste texto a definição e discussão da escola unitária em Gramsci, é relevante ressaltar o que o próprio Gramsci destacou no Caderno 12: "La crisis tendrá una solución que racionalmente debería seguir esta línea: escuela única inicial de cultura general, humanista, formativa, que equilibre justamente el desarrollo de las capacidades de trabajar manualmente (técnicamente, industrialmente) y el desarrollo de las capacidades del trabajo intelectual. De este tipo de escuela única, a través de experiencias repetidas de orientación profesional, se pasará a una de las escuelas especializadas o al trabajo productivo". (GRAMSCI, 1981, p. 367).

Recebido em abril-13

Aprovado em outubro-13 